\title{
Peculiarities of the physico-chemical interaction in ternary systems of magnesium with two rare-earth metals of different subgroups
}

\author{
L.L. ROKHLIN ${ }^{1}$, E.A. LUKYANOVA ${ }^{1}$, T.V. DOBATKINA ${ }^{1}$, I.G. KOROLKOVA ${ }^{1}$ \\ ${ }^{1}$ A.A. Baikov Institute of Metallurgy and Materials Science, Russian Academy of Sciences, \\ Leninsky Prosp. 49, 119991 Moscow, Russia \\ * Corresponding author. Tel.: +7-499-135-8660; fax: +7-499-135-8680; e-mail: rokhlin@imet.ac.ru
}

Dedicated to Evgen I. Gladyshevskii (1924-2012)

Received November 18, 2013; accepted June 26, 2014; available on-line November 10, 2014

This work analyzes and summarizes the results of an investigation of ternary phase diagrams of magnesium with two rare-earth metals of different subgroups, conducted in IMET RAS in connection with the development of high-temperature magnesium alloys. During this investigation a number of regularities in the constitution of the studied phase diagrams were discovered. They allow explaining the effect of the applied alloying elements on the properties of magnesium alloys. They also make it possible to predict the phase diagram type of magnesium with other rare-earth metals and their properties.

Magnesium alloys / Rare earth metals / Phase diagram

\section{Introduction}

Alloying of magnesium alloys with rare-earth metals (REM) provides significant increase of strength, especially at elevated (up to $300{ }^{\circ} \mathrm{C}$ ) temperatures [1]. The phase diagrams of metals can be considered as the base for a scientific approach to the development of industrial alloys for various purposes. Therefore the investigation of phase diagrams of magnesium with rare-earth metals has been given high attention. During a long period, the investigation of phase diagrams of magnesium systems with rare-earth metals was performed with the aid of members of the Department of Inorganic Chemistry of the Ivan Franko State University of Lviv, headed by Prof. Dr. Evgen Ivanovych Gladyshevskii. Professor E.I. Gladyshevskii and his colleagues at the department had great experience in the determination of crystal structures of intermetallic compounds, among others magnesium compounds with rare-earth metals [2]. The involvement of high-class professionals allowed obtaining reliable information about the phase equilibria and the crystal structures of the phases formed in the investigated systems [3-6].

The ternary phase diagrams of magnesium systems with rare-earth metals can be divided into two groups. The first group of magnesium systems includes as one component a rare-earth metal and as the other component a non-rare-earth metal. The second group consists of systems that include, besides magnesium, two rare-earth metals. The latter systems are of especial interest, because in industry the rare-earth metals are usually used in the form of mixtures, enriched with one of the rare-earth elements: cerium, neodymium, yttrium, etc. It is important to know how and why a proportion of the rare-earth elements in the mixture affect the properties of magnesium. Moreover, systems of this type are of interest, as it may be expected that better properties can be achieved for a certain combination of rare-earth metals, than using each rare-earth metal on its own. An analysis of ternary phase diagrams of magnesium with two rareearth metals belonging to different subgroups: yttrium or cerium ones, has been carried out in this work, since joint alloying of magnesium by rare-earth metals of different subgroups produce a clear raise of the ageing strength [7].

\section{Results and discussion}

The phase equilibria in the Mg-Y-Ce [3], Mg-Y-La [5,8], Mg-Y-Nd [9,10], Mg-Y-Sm [11,12], Mg-Sm-Gd [13,14], Mg-Sm-Tb [15,16], and $\mathrm{Mg}-\mathrm{Sm}-\mathrm{Er}$ [17] systems have been investigated by DTA, optical microscopy, XRD, electron microprobe analysis, and measurements of resistivity and microhardness. Focusing on practical applications, the research was limited to magnesium-rich concentrations. The selection of yttrium, lanthanum, and cerium as alloying elements was motivated by their use in industrial magnesium alloys, while the 
choice of samarium, gadolinium, dysprosium, and terbium was based on the search for new advantageous alloying additions for the improvement of the mechanical properties of magnesium alloys at both ambient and elevated temperatures. The phases in equilibrium with the magnesium solid solution, the temperature and character of the invariant transformations, if any, with the participation of the magnesium solid solution, the liquidus and solidus temperatures, the solubility of the alloying elements in the magnesium-based solid solution and its temperature dependence, were determined. On the basis of the studies of the $\mathrm{Mg}-\mathrm{Y}-\mathrm{La}, \mathrm{Mg}-\mathrm{Y}-\mathrm{Ce}$, $\mathrm{Mg}-\mathrm{Y}-\mathrm{Nd}, \mathrm{Mg}-\mathrm{Y}-\mathrm{Sm}, \mathrm{Mg}-\mathrm{Sm}-\mathrm{Gd}, \mathrm{Mg}-\mathrm{Sm}-\mathrm{Tb}$, and $\mathrm{Mg}-\mathrm{Sm}-\mathrm{Er}$ phase diagrams, the isothermal and polythermal sections of the phase diagrams and the projections of the liquidus and solidus surfaces were constructed for magnesium-rich alloys.

All the systems containing two rare-earth metals of the cerium and yttrium subgroups are characterized by the absence of phases in equilibrium with the magnesium solid solution, except the compounds nearest to magnesium in the binary systems adjacent to the magnesium corner. These compounds have different crystal structures and, thus, cannot form continuous solid solutions. In this case, the system undergoes a four-phase invariant transformation with the participation of liquid, magnesium solid solution, and both compounds, or, rather, solid solutions based on them, since each compound of a rare-earth metal generally dissolves significant amounts of other rareearth metals. According to the DTA data, the fourphase invariant transformations in the systems can be of the eutectic type: $\mathrm{L}=(\mathrm{Mg})+\mathrm{Mg}_{24} \mathrm{Y}_{5}+\mathrm{Mg}_{12} \mathrm{Ce}$ [3], $\mathrm{L}=(\mathrm{Mg})+\mathrm{Mg}_{24} \mathrm{Y}_{5}+\mathrm{Mg}_{17} \mathrm{La}_{2}[8], \mathrm{L}=(\mathrm{Mg})+$ $\mathrm{Mg}_{24} \mathrm{Y}_{5}+\mathrm{Mg}_{9} \mathrm{Nd}$ [10], or transition type: $\mathrm{L}+$ $\mathrm{Mg}_{24} \mathrm{Y}_{5}=(\mathrm{Mg})+\mathrm{Mg}_{6,2} \mathrm{Sm}[11], \mathrm{L}+\mathrm{MgGd}_{5}=(\mathrm{Mg})+$ $\mathrm{Mg}_{41} \mathrm{Sm}_{5}$ [14], L $+\mathrm{Mg}_{24} \mathrm{~Tb}_{5}=(\mathrm{Mg})+\mathrm{Mg}_{41} \mathrm{Sm}_{5}$ [15] The compositions of the compounds are given according to the cited publications. Fig. 1 and Fig. 2 show examples of the solidification surfaces for the $\mathrm{Mg}-\mathrm{Y}-\mathrm{La}$ [8] (eutectic) and $\mathrm{Mg}-\mathrm{Sm}-\mathrm{Tb}$ [15] (transition type) systems. The temperatures of the invariant equilibria of all the systems studied here are indicated in Table 1 . Note the regular character of the change in the invariant transformation temperature for magnesium-yttrium alloys with a rare-earth metal of the cerium subgroup. With increasing atomic number of the rare-earth metal, the invariant transformation temperature decreases. The same is observed for the magnesium-samarium alloys with rare-earth metals of the yttrium subgroup.

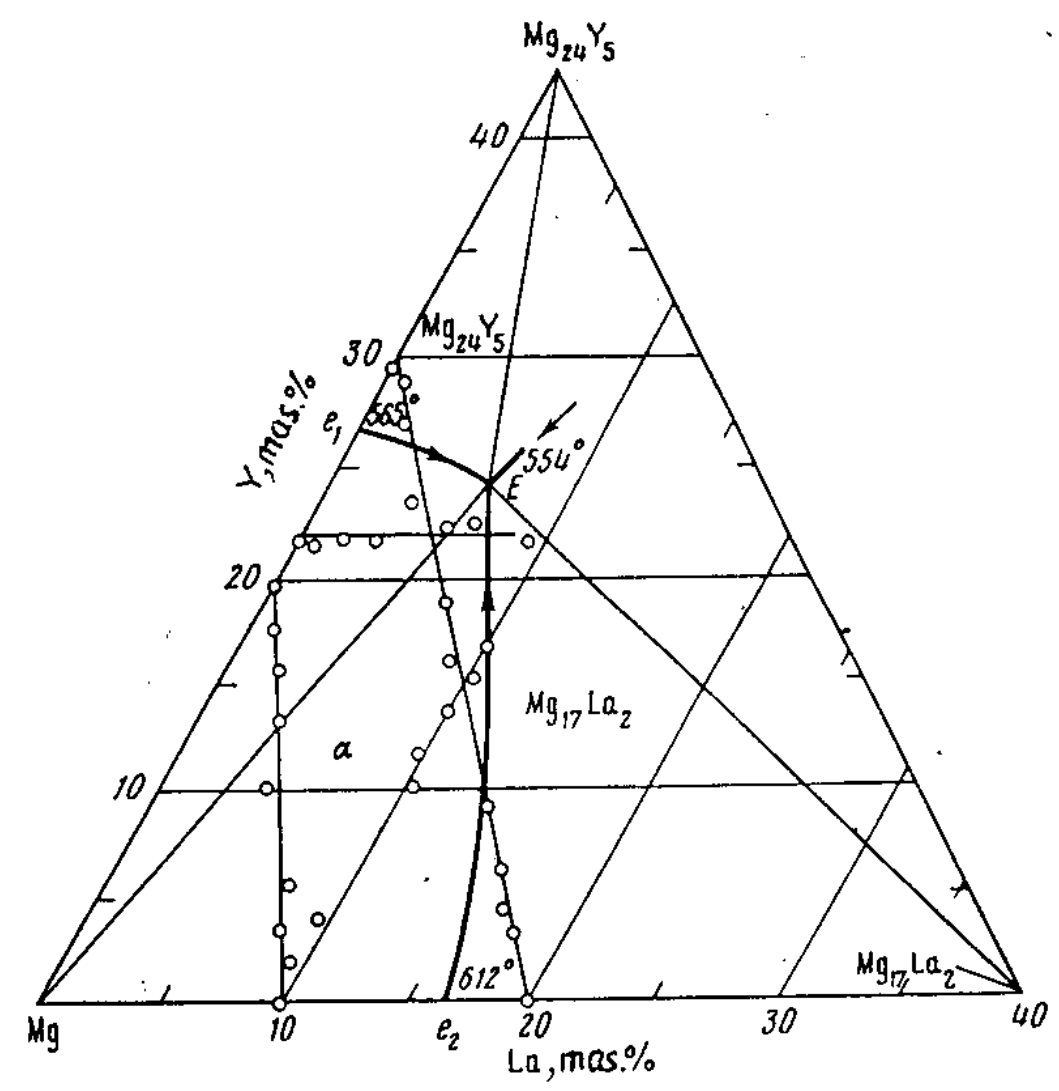

Fig. 1 Projection of the solidification surface in the Mg-rich corner of the Mg-Y-La phase diagram [8]. 


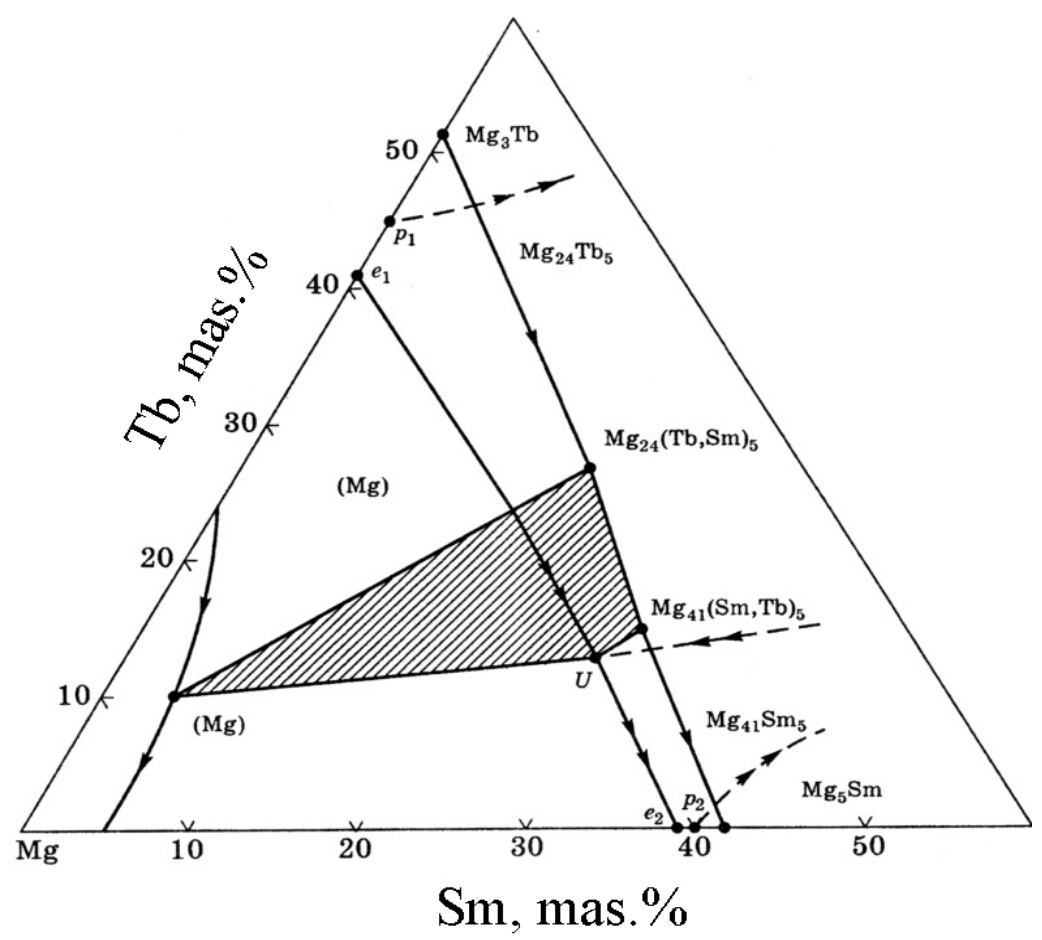

Fig. 2 Projection of the solidification surface in the Mg-rich corner of the $\mathrm{Mg}-\mathrm{Sm}-\mathrm{Tb}$ phase diagram [15].

Table 1 Temperatures of invariant equilibria in ternary systems of magnesium with two rare-earth metals of different subgroups.

\begin{tabular}{c|c|c|c|c|c|c}
\hline System & $\mathrm{Mg}-\mathrm{Y}-\mathrm{La}$ & $\mathrm{Mg}-\mathrm{Y}-\mathrm{Ce}$ & $\mathrm{Mg}-\mathrm{Y}-\mathrm{Nd}$ & $\mathrm{Mg}-\mathrm{Y}-\mathrm{Sm}$ & $\mathrm{Mg}-\mathrm{Sm}-\mathrm{Gd}$ & $\mathrm{Mg}-\mathrm{Sm}-\mathrm{Tb}$ \\
\hline $\begin{array}{c}\text { Temperature of invariant } \\
\text { equilibrium, }{ }^{\circ} \mathrm{C}\end{array}$ & 554 & 543 & 536 & 534 & 542 & 539 \\
\hline
\end{tabular}

The isothermal sections of the phase diagrams at different temperatures were constructed to determine the solubility of the rare-earth metals in solid magnesium, as well as the positions of the phase fields. Fig. 3 and Fig. 4 show the isothermal sections of the $\mathrm{Mg}-\mathrm{Sm}-\mathrm{Gd}$ [13] and $\mathrm{Mg}-\mathrm{Sm}-\mathrm{Er}$ [17] systems at $500{ }^{\circ} \mathrm{C}$. The expansion of the two-phase fields in the isothermal sections indicates the solubility of one rareearth metal in the binary compound of the other rareearth metal. The results of local spectral analyses of alloys belonging to the systems under study showed the solubility of one rare-earth metal in the binary magnesium compound of the other rare-earth metal, and the solubility can be significant (Table 2).

The solubility of the two rare-earth metals in solid magnesium is remarkable. As shown in our studies, each of the two rare-earth metals affects the solubility of the other rare-earth metal, but the total solubility of the two rare-earth metals is always intermediate between the solubilities of the metals in the binary systems. This is evident from the fact that the field of the magnesium solid solution in the alloys is considerably smaller than the area of a parallelogram with sides corresponding to the solubilities of each of the rare-earth metals in solid magnesium (describing the case where each of the components does not affect the solubility of the other one). The same character is exhibited by the solubility of yttrium and cerium [3], yttrium and lanthanum [5], yttrium and neodymium [9], yttrium and samarium [12], and samarium and terbium [16] in solid magnesium.

This regularity is important for commercial alloys containing rare-earth metals, since it indicates that the presence of a component that is less soluble in magnesium can decrease the strengthening efficiency of a more soluble component. On the other hand, the combination of two rare-earth metals forming magnesium-base compounds with different structures can provide a certain benefit, allowing one to use the combination of strengthening by two different reinforcing phases. Moreover, taking into account the mutual solubility of rare-earth metals 


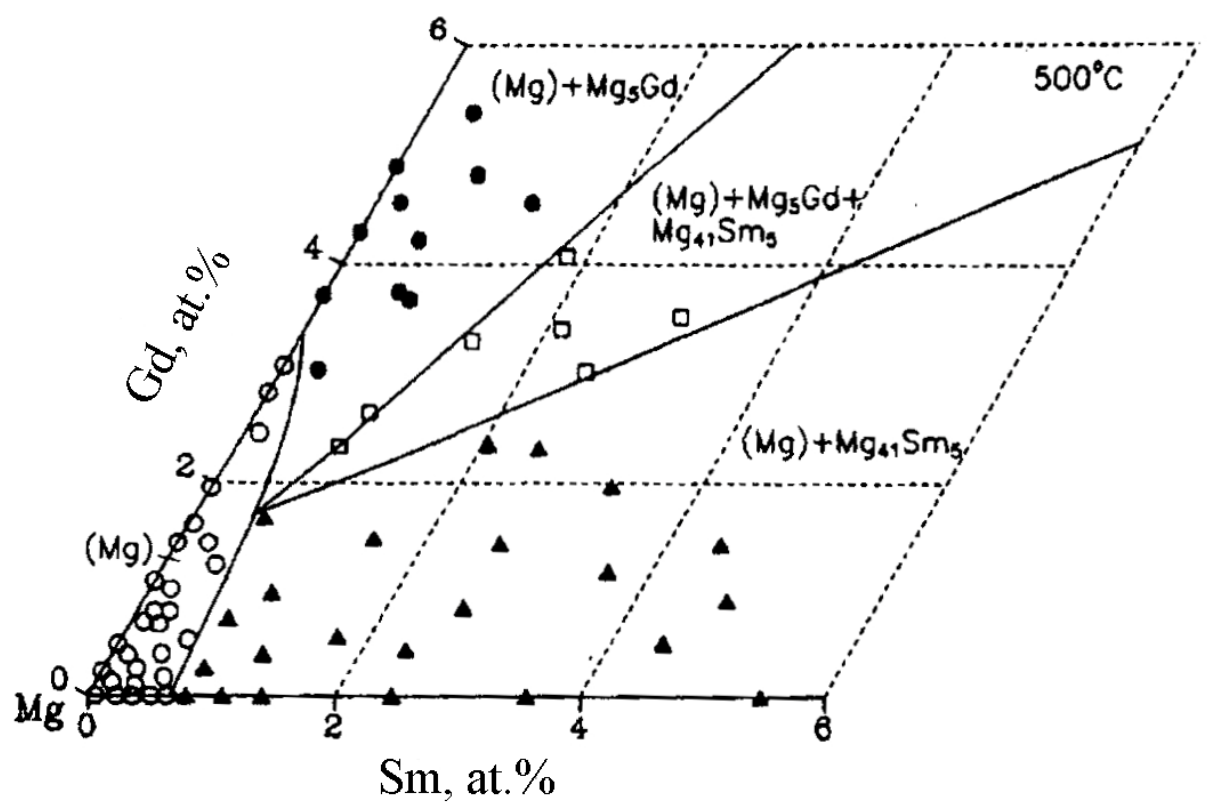

Fig. 3 Isothermal section of the $\mathrm{Mg}$-rich region of the $\mathrm{Mg}-\mathrm{Sm}-\mathrm{Gd}$ system at $500{ }^{\circ} \mathrm{C}$ [13].

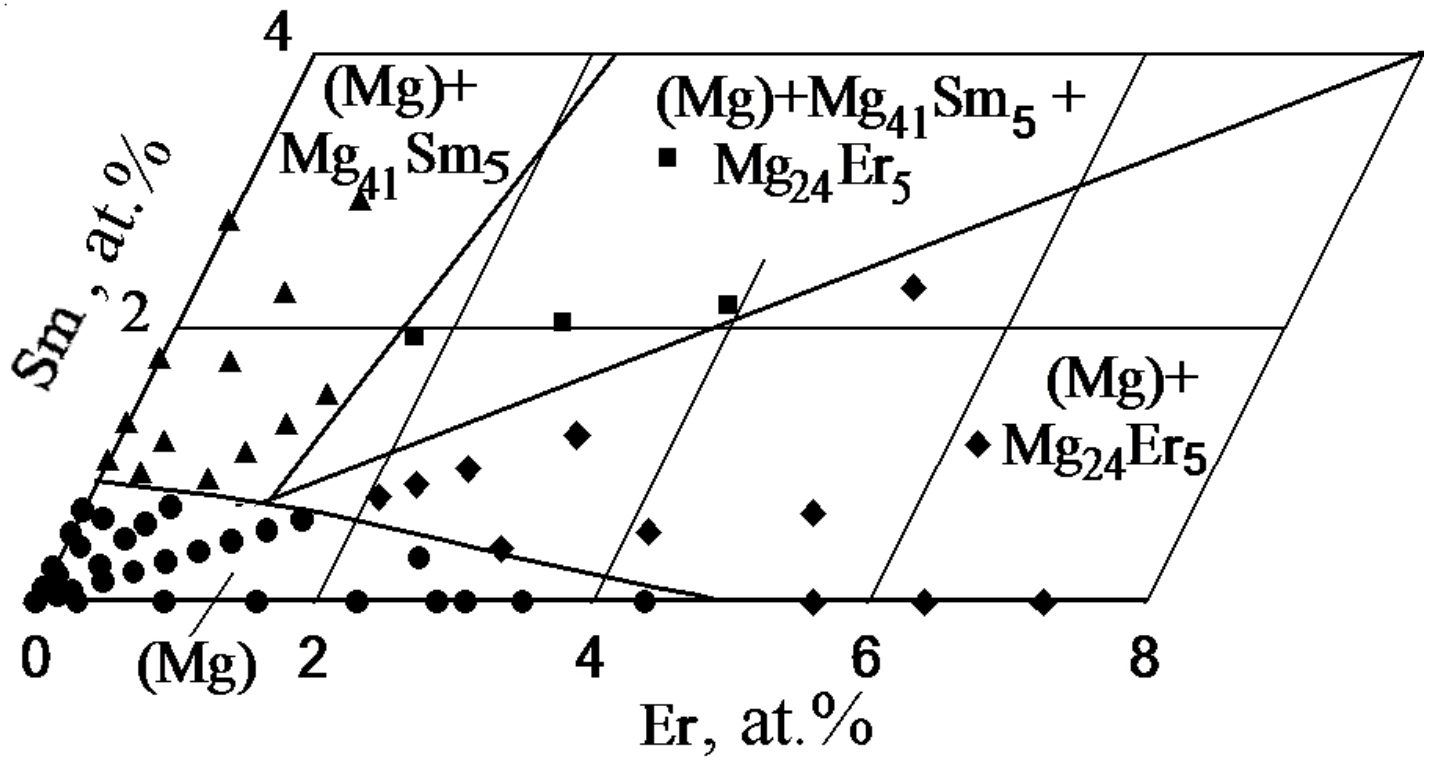

Fig. 4 Isothermal section of the $\mathrm{Mg}$-rich region of the $\mathrm{Mg}-\mathrm{Sm}-\mathrm{Er}$ system at $500^{\circ} \mathrm{C}$ [17].

Table 2 Composition of phases in equilibrium at $500^{\circ} \mathrm{C}[16]$.

\begin{tabular}{c|c|c|c}
\hline \multirow{2}{*}{ Phase } & \multicolumn{3}{|c}{ Composition (mass\%) } \\
\cline { 2 - 4 } & $\mathrm{Mg}$ & $\mathrm{Sm}$ & $\mathrm{Tb}$ \\
\hline$(\mathrm{Mg})$ & 85.05 & 3.44 & 11.51 \\
$\mathrm{Mg}_{41} \mathrm{Sm}_{5}$ & 57.00 & 28.70 & 14.30 \\
$\mathrm{Mg}_{24} \mathrm{~Tb}_{5}$ & 52.10 & 21.30 & 26.60 \\
\hline
\end{tabular}


in equilibrium binary phases, one can assume that this solubility also remains in the products of the decomposition of supersaturated magnesium solid solution and affects the ageing kinetics of ternary alloys [18].

The peculiarities of the ternary phase diagrams studied for systems of magnesium with two rare-earth metals of different subgroups are assumed to be typical for all phase diagrams of this kind, and can be used for the prediction of phase equilibria of not yet investigated phase diagrams of magnesium with rareearth metals.

\section{Conclusions}

1. Ternary phase diagrams of magnesium with two rare-earth metals of different subgroups are characterized by the absence of additional compounds with magnesium, excluding the nearest magnesium ones in the corresponding binary systems, and the existence of an invariant reaction with participation of the magnesium solid solution, the binary compounds and a liquid phase.

2. The overall solubility of two rare-earth metals, belonging to different subgroups, in magnesium is intermediate between the values observed in the binary systems.

3. Significant solubility of each rare-earth metal in compounds of the other one has been established.

\section{References}

[1] L.L. Rokhlin, Magnesium Alloys Containing Rare-Earth Metals, Taylor and Francis, LondonNewYork., 2003, 245 p.

[2] E.I. Gladyshevskii, O.I. Bodak. Crystal Chemistry of Rare-Earth Intermetallic Compounds, Vyshcha Shkola, Lviv, 1982, 255 p. (in Russian).
[3] M.E. Drits, E.M. Padezhnova, T.V. Dobatkina, E.A. Voitekhova, V.V. Kinzhybalo, Izv. Akad. Nauk SSSR, Met. (6) (1981) 206-210.

[4] V.V. Kinzhybalo, L.L. Rokhlin, N.P. Abrukina, Izv. Akad. Nauk SSSR, Met. (1) (1985) 204-205.

[5] T.V. Dobatkina, E.V. Muratova, V.V. Kinzhybalo, A.T. Tyvanchuk, Izv. Akad. Nauk SSSR, Met. (1) (1984) 211-214.

[6] E.V. Muratova, T.V. Dobatkina, V.V. Kinzhybalo, Izv. Akad. Nauk SSSR, Neorg. Mater. 25(1) (1989) 66-70.

[7] L.L. Rokhlin, T.V. Dobatkina, N.I. Nikitina, I.E. Tarytina., V.N. Timofeev, Fiz. Met. Metalloved. 100(2) (2005) 70-75.

[8] E.M. Padezhnova, T.V. Dobatkina, E.V. Muratova, Izv. Akad. Nauk SSSR, Met. (4) (1983) 194-197.

[9] Z.A. Sviderskaya, E.M. Padezhnova, Izv. Akad. Nauk SSSR, Met. (6) (1971) 200-204.

[10] Z.A. Sviderskaya, E.M. Padezhnova, Structure and Properties of Light Alloys, Nauka, Moscow, 1971, pp. 6-10 (in Russian).

[11] M.E. Drits, L.L. Rokhlin, N.P. Sirchenko, Izv. Vyssh. Uchebn. Zaved., Tsvetn. Metall. (6) (1983) 78-82.

[12] M.E. Drits, L.L. Rokhlin, N.P. Abrukina, Izv. Akad. Nauk SSSR, Met. (5) (1984) 199-204.

[13] L.L. Rokhlin, N.I. Nikitina, T.V. Dobatkina, J. Alloys Compd. 239 (1996) 209-213.

[14] L.L. Rokhlin, T.V. Dobatkina, N.I.Nikitina, Metally (4) (1997) 109-112.

[15] E.A. Lukyanova, L.L. Rokhlin, T.V. Dobatkina, I.G. Korolkova, Metally (3) (2011) 99-105.

[16] L.L. Rokhlin, T.V. Dobatkina, E.A. Lukyanova, I.G. Korolkova, A.S. Polikanova, Metally (4) (2010) 99-106.

[17] L.L. Rokhlin, N.I. Nikitina, Metally (2) (2002) 119-123.

[18] E.A. Lukyanova, L.L. Rokhlin, T.V. Dobatkina, N.Yu. Tabachkova, Fiz. Met. .Metalloved. 114(7) (2013) 658-669. 